\title{
Design, assembly and experimental tests of a Savonius type wind turbine
}

\author{
Diseño, montaje y pruebas experimentales de una turbina eólica tipo Savonius
}

\author{
E. A. Salazar-Marín ; A. F. Rodríguez-Valencia iD
}

\begin{abstract}
The present research project focuses on the development of a Savonius type wind turbine, where a literature review is initially carried out to recognize the appropriate parameters for its design such as turbulence, wind velocity, and air density, followed by a design methodology to achieve the dimensioning by means of resistance calculation and selection of component materials, after having the final concept defined. Through the use of computational tools such as Solidworks, Inventor, Simulation Mechanical, the design stage was validated through simulation to study the dynamic fluid behavior and the components were modeled to evaluate their response to wind loads, verifying their resistance. Subsequently, according to the modeling, the detailed drawings of the components of the turbine were obtained, with which they were assembled. Finally, having the physical model of the Savonius wind turbine, experimental tests were carried out in the laboratory of Fluids and Hydraulic Machines of the Technological University of Pereira. As an important result of analysis (simulation and experimental tests) a power coefficient of 0,2 was obtained and shaft mechanical power varies with cubic velocity wind. Power over $100 \mathrm{~W}$ can be reached with sweep area $1 \mathrm{~m}^{2}$ and $10 \mathrm{~m} / \mathrm{s}$ velocity turbines.
\end{abstract}

Index Terms - Savonius wind turbine, wind energy, wind speed, power coefficient, mechanical power.

Resumen--- El presente proyecto de investigación se centra en el desarrollo de un aerogenerador de tipo Savonius, en el que inicialmente se realiza una revisión de la literatura para reconocer los parámetros apropiados para su diseño, como la turbulencia, la velocidad del viento y la densidad del aire, seguido de una metodología de diseño para lograr el Dimensionamiento mediante cálculo de resistencia y selección de materiales componentes, luego de haber definido el concepto final. Mediante el uso de herramientas computacionales como Solidworks, Inventor, Simulation Mechanical, la etapa de diseño se validó a través de la simulación para estudiar el comportamiento dinámico del fluido y los componentes se modelaron para evaluar su respuesta a las cargas de viento, verificando su resistencia. Posteriormente, de acuerdo con el modelado, se obtuvieron los planos detallados de los componentes de la turbina, con los cuales fueron ensamblados. Finalmente, teniendo en cuenta el modelo físico del aerogenerador

This manuscript was sent on February 25, 2019 and accepted on September 23,2019 . It was developed with own resources to build the turbine, and tests were carried out in fluids laboratory of university (UTP).

E. A. Salazar-Marín, is with Technology Department of Technological University of Pereira, CP. 660003 (e-mail: edgarsalazar@utp.edu.co).
Savonius, se realizaron pruebas experimentales en el laboratorio de fluidos y máquinas hidráulicas de la Universidad Tecnológica de Pereira. Como resultados importantes del análisis (simulación y experimentación) se obtuvo que el coeficiente de potencia de la turbina eólica tiene un valor de 0,2 y la potencia mecánica en el eje de la turbina varía con el cubo de la velocidad del viento. Con turbinas de este tipo se pueden lograr potencias mayores a $100 \mathrm{~W}$ con área de barrido de $1 \mathrm{~m}^{2}$ y velocidades de viento de $10 \mathrm{~m} / \mathrm{s}$.

Palabras claves - Turbina eólica Savonius, energía eólica, velocidad del viento, coeficiente de potencia, potencia mecánica.

\section{INTRODUCTION}

$\mathrm{W}$ IND energy is a renewable energy source which can be exploited to transform it through mechanical devices such as a wind turbine, where it converts the kinetic energy of the wind into mechanical energy of the axis [1] [2]. There are mainly two large groups of wind turbines that have been designed for such process and are classified according to the orientation of the turbine shaft. They are vertical axis turbines and horizontal axis turbines [3]. The horizontal axis turbines that are found in the majority of wind farms are constituted by: foundation, tower, gondola with power train, rotor and paddles. According to the Guide on Mini-Wind Technology [4], in the case of horizontal axis wind turbines, the rotor can be windward, that is, in the direction of wind incidence in front of the tower, or to leeward, in which case the rotor is located behind the tower in the dominant direction of the wind. Most of the wind turbines are rotor to windward of the tower, which means that they require some guidance system. In the case of a downwind rotor, the rotor is self-orientating, which simplifies its design.

Horizontal axis turbines are more efficient than vertical axis turbines, are more proven, are cheaper and there are many products to choose from. However, they have the difficulty of supporting the continuous orientations and their efficiency is reduced by operating in a turbulent regime.

A. F Rodríguez-Valencia, is MSc of Technological university of Pereira and currently he works such a Professor in Energy department of Autonomous University of Occident (Cali) (e-mail: afrodriguezv@uao.edu.co). 
Vertical axis turbines are oriented in the predominant wind direction due to their symmetry, are less sensitive to high turbulence conditions and produce less vibration, these conditions make them ideal for integrations in residential, urban and even buildings [5]. On the other hand, their efficiency is lower compared to horizontal axis and they are not very proven since they are now in full development. There are two types of vertical turbines, those based on drag and those based on lift. The first one is less efficient, but usually less robust.

Within the vertical axis turbines are the Savonius type turbines which are used to convert the wind power in torque on a rotating axis. "The vertical axis turbines were invented by the Finnish engineer Sigurd J. Savonius in 1922", they can start with a slow wind velocity, being very easy to manufacture; It has a small turning speed and its performance is relatively low.

The research work emphasizes Designing the physical components of a wind turbine type Savonius based on the design parameters of this type of rotors and the parameters that characterize the use of wind energy such as wind speed, air density of a region and turbulence. Having the selected final concept and the sizing of the wind turbine, modeling and simulation of the rotor is carried out. Subsequently, the construction of the wind turbine is made according to the obtained plans and finally experimental tests are carried out in the laboratory.

\section{DESIGN PARAMETERS OF THE SAVONIUS TYPE WIND TURBINE}

Several investigations [6], [7], [8] have been made regarding the study of the performance of the Savonius rotor from different geometrical configurations of its rotor. These studies have been made based on numerical computational analysis taking advantage of the use of CFD (Computational Fluids Dynamics) and experimental tests in wind tunnels. The different configurations that have developed over time, have looked for an improvement in the performance of the aerodynamic behavior of the Savonius rotor. That is why the geometric configuration is fundamental in terms of its performance, the configuration that has been said for a Savonius rotor is determined by the following design parameters of the rotor:

- Rotor aspect ratio.

- Area swept by the rotor blades.

- Geometric shape of the blades (profile, length of rope).

- Relationship of overlap and spacing between the blades.

- Number of blades and stages.

- Other additional components to the rotor structure (axis, sail-flag effect, support structure, etc.).

The geometric shape of the blades is going to have a semicircular profile which will be obtained from a PVC tube of 6 inches in diameter, keeping the traditional shape of the Savonius rotor blades. Figure 1 shows the profile of the blade with its dimensions.

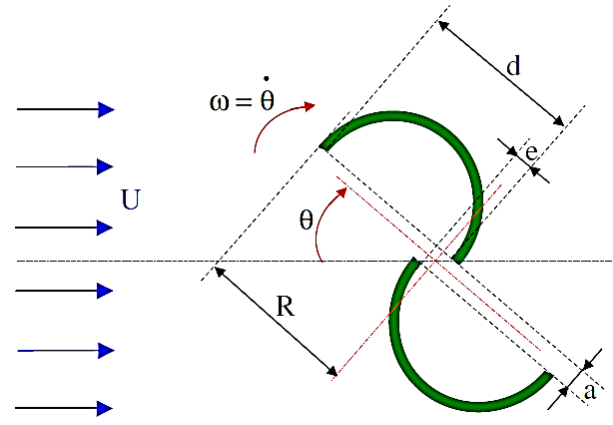

Fig. 1. Profile of the blade. [7]

The overlap relation is a dimensionless parameter that relates the perpendicular distance between the cross and the center of rotation with the chord line length which is given as (1) [8]:

$$
\text { overlap relation }=R_{S}=\frac{e}{d}
$$

Where $e$ is the distance between the inner tips of the blades that have overlap and $d$ corresponds to the value of the semicylindrical blade diameter which in turn coincides with the length of the rope. Figure 2 schematizes the relationship that has been said.

In this way, the overlap ratio is a design parameter of the Savonius rotor, several authors have studied the optimal overlap ratio in rotors with 2 blades, which is the particular case of the present investigation. According to Menet, $\mathrm{J}$ et al. [7] the overlap ratio in a two-bladed rotor is in the range of 0.15 to 0.3 times the length of the blade.

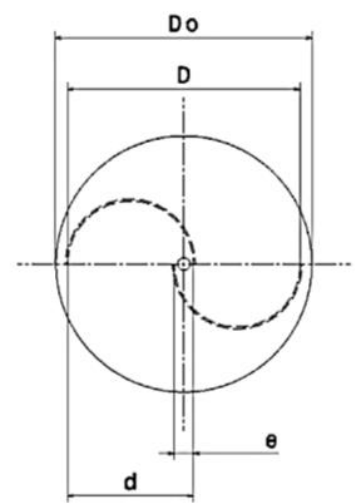

Fig. 2. Schematization of the geometric parameters and the overlap ratio for a two-bladed rotor. [8]

The aspect ratio is a dimensionless parameter which involves the height of the rotor $\mathrm{H}$ and the diameter of the circle that is formed when rotating the tips of the blades called diameter of the rotor D. Figure 3 shows the geometrical values of the rotor where the aspect ratio can be seen. 

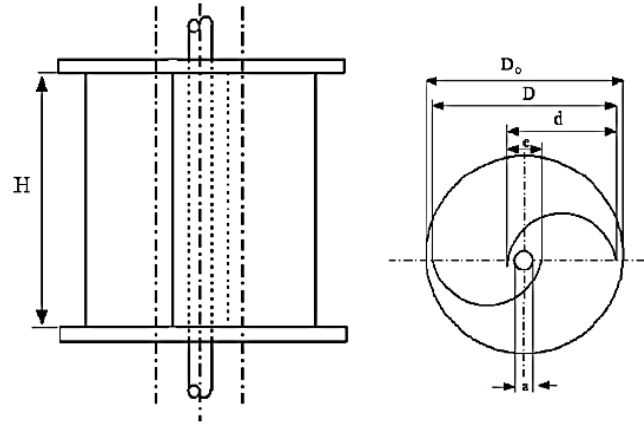

Fig. 3. Rotor aspect ratio. [9]

The equation that relates the height of the rotor $\mathrm{H}$ with the diameter of the rotor $\mathrm{D}$, is given by (2) [9]:

$$
\text { rotor aspect ratio }=\alpha_{R A}=\frac{H}{D}
$$

The swept area of a rotor is generally defined as the projected area that is formed during the rotation of the blades. In the case of a Savonius-type rotor, the projected area corresponds to the area of a rectangle. This can be seen in Figure 4 which schematically represents the projection of this area.

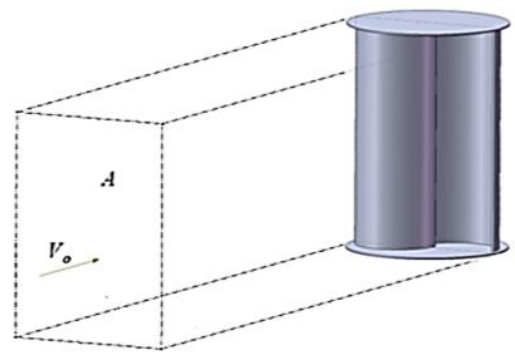

Fig. 4. Representation of the swept area of a Savonius rotor. [6]

Thus the calculation of the swept area by the Savonius rotor will be given by (3) [10]:

$$
\text { swept area }=A_{s}=H_{r} \cdot D
$$

The dimensioning of the final plates of the rotor is carried out based on the criteria proposed by Akwa et al. [6], which states that the thickness of the final plates must be minimum which is relative to the height of the rotor. It also recommends a value of 1.1 times the value of the diameter of the rotor $D$ for the calculation of the diameter of the final plates $D_{e p}$. This is how the equation for the calculation of the diameter of the final plates is given by (4) [6]:

$$
D_{e p}=1,1 \cdot D
$$

The value of the final plate thickness is influenced by the nature of the material and the moment of inertia of the rotor. Torres, Daniela M. [11] made a decision matrix to select a material of the blades and end plates in which she selected as best option the 16 gauge galvanized sheet that corresponds to a thickness of $1.52 \mathrm{~mm}$. The number of blades is a fundamental structural parameter that conditions the performance of the Savonius rotor, as stated above. Rotors of two blades have a greater variation in the torque induced in the axis with respect to those of three or more blades; this variation is presented, since for a two-bladed rotor the angle of separation between them is $180^{\circ}$, in this way every $180^{\circ}$ a maximum torque is presented because the force received by the blades of the turbine is maximum at that point. This can be observed in the curve of torque against angle of attack presented by Hadi [10], which is shown in Fig. 5.

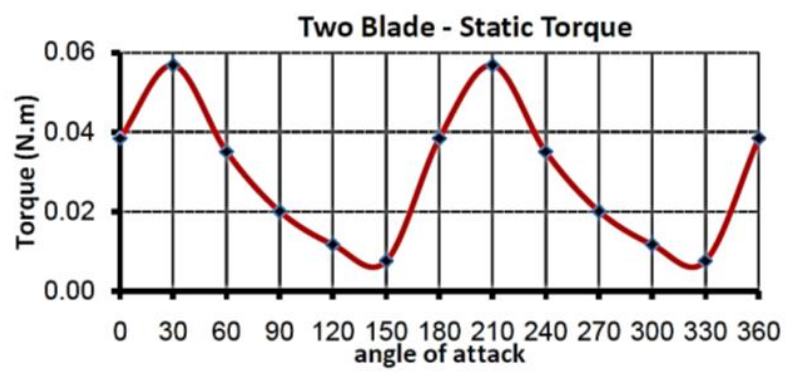

Fig. 5. Variation of the static torque against the angle of attack of a Savonius turbine with two blades [10].

As regards a rotor with three or more blades, the variation of the torque with respect to the angle of attack of the air flow tends to be more constant, also allowing the handling of highspeed ratios at the tips. In the particular case of the design of the rotor that is going to be carried out, a two-bladed rotor was selected, since, although the torque presents a greater variation as a function of the angle of attack, the power coefficient curve in function of the speed ratio at the tips presents higher values of power coefficient. The following curve, Fig. 6, shows the comparison of the curves of the power coefficient as a function of the wind speed.

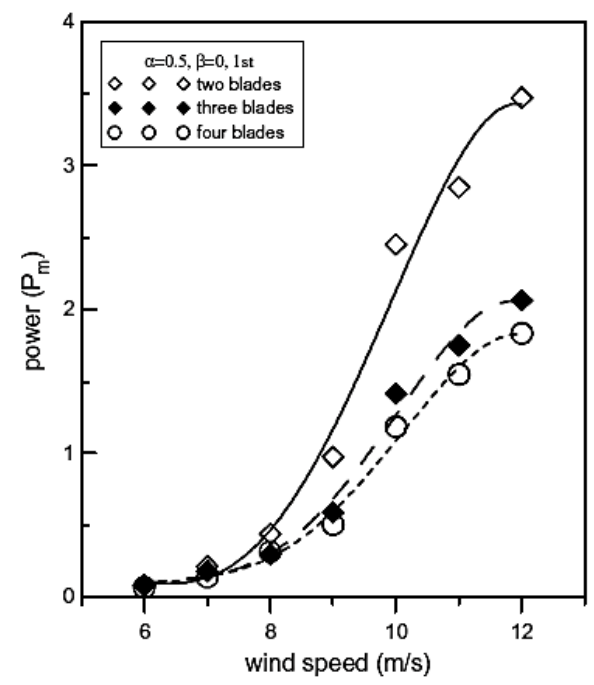

Fig. 6. Power curves against wind speed of a rotor of 2, 3 and 4 blades [9].

The Savonius rotor stages represent the superimposition of simple Savonius rotors where they are out of phase at a certain angle [12], which is observed in Fig. 7. 


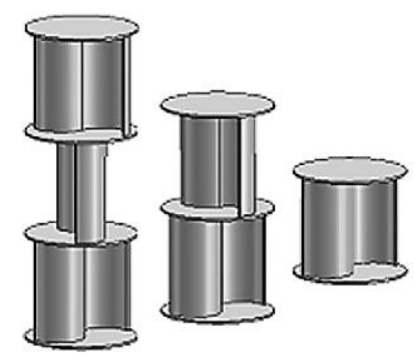

Fig. 7. Savonius rotors with different stages [12].

For the present design a two-stage rotor is considered, since multiple stages are considered mainly for two-bladed rotors, in addition to the advantages of the reduction in moment fluctuations.

Fig. 8 shows the power coefficient as a function of wind speed for two-stage rotors with 2, 3 and 4 blades.

An initial parameter to carry out the design of the turbine is the speed of the free wind current. That is why the location of the turbine is important. According to the Atlas of the Wind [13], the average wind speed for the municipalities of Guática and Quinchía is approximately $8 \mathrm{~m} / \mathrm{s}$. These sites are suitable places within the department of Risaralda for the location of a Savonius wind turbine, given its proximity and which can become test sites for this type of wind turbines. The average annual wind speed at the Technological University of Pereira according to the meteorological unit is $0.77 \mathrm{~m} / \mathrm{s}$ and according to data collected by Torres D [11] the average annual speed of the meteorological unit of the Mundo Nuevo neighborhood is $3.81 \mathrm{~m} / \mathrm{s}$ for the year 2014. After having made the analyzes of the sites mentioned above, a wind speed of $U_{\infty}=8 \mathrm{~m} / \mathrm{s}$ is set as the design parameter value, so that the turbine may be suitable for experimental testing in any of the afore mentioned sites.

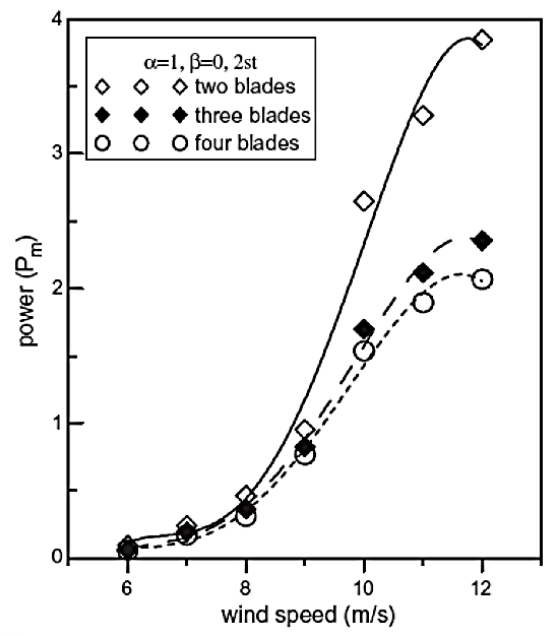

Fig. 8. Power coefficient curves versus wind speed for a 2 -stage rotor with 2,3 and 4 blades [9].

The Tip Speed Ratio TSR ( $\lambda$ ) [14] is a dimensionless parameter that relates the tangential speed of the tips of the blade with the speed of the free wind current, in addition to representing the behavior of a particular type of a wind turbine, which is applicable for the VAWT (Vertical Axis Wind Turbine) and HAWT (Horizontal Axis Wind Turbine), the TSR is referred to (5).

$$
T S R=\lambda=\frac{\Omega \cdot R}{U_{\infty}}
$$

Where $\Omega$ is the angular velocity of the rotor, $R$ is the distance from the center of rotation of the rotor to the tip of the blade. The Reynolds number is a dimensionless parameter used in the study of fluid flow through turbomachinery and flow systems, which relates inertial forces to viscous forces [12]. For a Savonius type wind turbine the Reynolds number is defined in equation (6).

$$
R e=\frac{\rho \cdot U_{\infty} \cdot D}{\mu}
$$

Where $\rho$ is the density of air, $U_{\infty}$ is the velocity of the free wind current, $\mathrm{D}$ is the diameter of the rotor and $\mu$ is the dynamic viscosity.

The Reynolds number plays a very important role in the wind tunnel experimentation of wind turbines when evaluating their aerodynamic performance, authors such as Niaz [15] conducted a study regarding the influence of the Reynolds number on the aerodynamic performance of a three-blade Savonius turbine with different overlap ratios in which it is expressed that: for high Reynolds numbers the modeled turbine without overlapping radius generates better aerodynamic coefficients, on the other hand for low Reynolds numbers the model with a radius of moderate overlap generates better results.

\section{DESIGN OF THE PHYSICAL COMPONENTS OF THE SAVONIUS TYPE WIND TURBINE}

The flow of air through the rotor induces forces on the blades and the different elements that make up the support structure. The determination of the loads due to air flow is based on studying the behavior of the flow and applying the different theories that are derived in the analysis of momentum. This is how, the analysis of the different forces that act on a turbine is convenient to treat separately by doing an aerodynamic analysis and then consider the forces that are transmitted between the different elements.

According to the established design parameters, the component parts by which this device will be composed are listed:

- 4 semicircular blades.

- 3 Final dishes.

- Turbine rotor shaft

- Support structure of the rotor.

$\cdot 2$ roller bearings.

The following is a brief description of the equations used in the design of the physical components of the turbine: 
DESIGN OF THE ROTOR: The tree design includes the following stages according to Vanegas, L [16]:

- Material selection.

- Constructive design.

- Verification of resistance: Static, to fatigue and dynamic loads.

- Verification of the rigidity: deflection by bending and slope of the elastic and deformation by torsion.

- Modal analysis.

Selection of shaft material. The most commonly used material in the manufacture of shafts is steel with low or medium carbon content. This material is recommended for the resistance of dynamic loads since it has fatigue limit and makes it suitable to support many load cycles. If additional properties such as corrosion resistance are required, a steel whose properties allow resistance to the required characteristics must be selected.

Calculation of rotor's weight. The determination of rotor's weight is made from the sum of the individual weights of each of the component elements.

The blades as defined in the preliminary design part, will be made of PVC material, the final plates that make up the rotor from AISI / SAE 1020 Cold Rolled steel sheet and the panels that are part of the rotor of acrylic material. The total weight of the rotor is determined by (7).

$$
\begin{aligned}
& F_{g T}=4 \cdot\left(\rho_{P V C} \cdot g \cdot \forall_{\text {aspa,PVC }}\right)+3 \cdot\left(\frac{F_{\text {g,plato final }}}{m^{2}} .\right. \\
& \left.A_{\text {plato final }}\right)+4 \cdot\left(\rho_{\text {acrílico }} \cdot g \cdot \forall_{\text {acrílico }}\right)+\forall_{\text {árbol }} . \\
& \rho_{\text {acero }} \cdot g+F_{g, \text { otros }}
\end{aligned}
$$

Calculation of the diameter of the rotor shaft. The calculation of the diameter of the rotor shaft will be made based on the theory of shaft design recommended by Vanegas, L [16]. Since a shaft performs a rotating movement, the loads it must support are variable over time. That is why the design equations of the Fatigue Theory are applied. In shaft fatigue analysis there are three methods which allow to calculate the shaft diameter required to adequately resist dynamic loads. These methods are the following:

- Von Mises method.

- Method adopted by Faires.

- ASME method.

The Von Mises method [16] is applied for this case after the different aerodynamic loads in the rotor have been determined, from which the required diameter of the shaft can be obtained to support dynamic loads over time, this is shown below in (8).

$$
\frac{1}{N}=\frac{\sqrt{\sigma_{e(m)^{2}+3 \tau_{e(m)}}}}{S_{y}}+\frac{\sqrt{\sigma_{e(a)^{2}+3 \tau_{e(a)}}}}{S_{n}}
$$

Where the stresses $\tau y \sigma$ can be calculated like this:

$$
\begin{gathered}
\tau_{e(m)}=K_{f m(T)} S_{S(m)} \\
\tau_{e(a)}=K_{f f(T)} S_{S(a)} \\
\sigma_{e(m)}=K_{f m(F)} S_{(F)(m)}+K_{f m(M)} S_{(M)(m)} \\
\sigma_{e(a)}=K_{f f(F)} S_{(F)(a)}+K_{f f(M)} S_{(M)(a)}
\end{gathered}
$$

$K_{f m}$ : Fatigue concentration factor at medium stress.

$K_{f f}:$ Fatigue stress concentration factor for finite life.

$K_{f}$ : Fatigue stress concentration factor for infinite life.

$N$ : Security factor.

$\sigma_{e}$ : Von Mises equivalent normal stress.

$\tau_{e}:$ Von Mises equivalent shear stress.

$S_{n}$ : Resistance to corrected fatigue.

It is important to clarify that several checks of the resistance of a shaft must be made such as resistance to vibrations, rigidity, modal analysis, etc., as previously established.

Selection of wind turbine bearings: Based on the diagrams of shear force and bending moment, it can be determined the radial loads that the supports of the shaft must bear, that's to say the bearings. In addition, the bearing located in the lower part must support the axial load that corresponds to the weight of the rotor. Therefore, the values of the reactions in the supports of the tree are:

$$
\begin{gathered}
F_{r A} \cong 15 \mathrm{~N} \\
F_{r D} \cong 15 \mathrm{~N} \\
F_{a D}=116 \mathrm{~N}
\end{gathered}
$$

Determination of the equivalent radial dynamic load: Because of the bearings supports A and D, support radial loads and axial loads, it is necessary to convert these load values into a single radial load value that would have an effect on the life of the equivalent bearing to the actual load applied, this load is known as "equivalent radial dynamic load $P_{r}$ " [17], which is determined by (9).

$$
P_{r}=X F_{r}+Y F_{a}
$$

$F_{r}$ : radial actual load $[\mathrm{N}], F_{a}$ : axial actual load $[\mathrm{N}], X$ : radial load factor, $Y$ : axial load factor.

Blade resistance evaluation: As indicated in the preliminary design, the blades are manufactured from a PVC pipe of 6 in., Based on these dimensions and material the blade's resistance must be evaluated, so for its analysis it is take the blade that is in the lower stage being this the most critical to support drag forces and weight loads. According to the loading arrangement and finding the most critical section, verification of resistance to tearing and crushing was carried out:

$\checkmark$ Calculation of tear stress [16]: It is determined with (10):

$$
S_{s, t e a r}=\frac{F}{2 \cdot b_{1} \cdot l_{1}}
$$

$b_{1}$ : Distance from the edge of the blade to the periphery of the hole $[\mathrm{m}]$, it is obtained of the planes, $l_{1}$ : Thickness of the material to be evaluated [m].

$\checkmark$ Crushing resistance [16]: Crushing resistance is determined with (11):

$$
S_{\text {crushing }}=\frac{F}{l \cdot d_{p}}
$$


Design of the rotor bolts [16]: The fastening elements that are used to join the blades with the final plates and the shaft with the blades are bolts subjected to static loads, so design theories for combined static loads are applied. The Octahedral shear stress Theory is applied to one of the points subjected to normal stress and the other subjected to shear stress by means of the equation 12.

$$
\left(\frac{s}{s_{y}}\right)^{2}+\left(\frac{s_{s}}{s_{s y}}\right)^{2}=\left(\frac{1}{N}\right)^{2}
$$

DESIGN OF THE STRUCTURE: The structure of the wind turbine will be composed of two trusses and six beams of which four are loaded beams and these supports the rotor, the other two beams are unloaded beams as they provide stability and rigidity to the structure. This must provide resistance to the loads to which the turbine will be subjected (wind loads, weight loads of the same structure and the rotor), rigidity, low deflection in the elements and minimum turbulence of the air flow that enters the rotor. Since the structure will be formed by two lateral trusses joined by beams, all its component elements must be designed, so the design of the structure is focused on the analysis of the trusses, analysis of the beams and later on the design of the Connection elements.

Loads that the structure supports. The main element of the wind turbine is the rotor to be this one, the component that supports different types of loads that in turn transmit them to the structure, on the other hand, the structure itself generates loads (own weight of this), that is why all possible loads must be considered. Initially the own weight of the structure is determined.

Truss design. The design of the truss consists of the dimensioning of its structural profiles evaluating their behavior to resistance, stability and deflection. The geometric shape of the truss is composed of structural profiles interconnected in nodes by means of brackets, which is shown in Fig. 9.

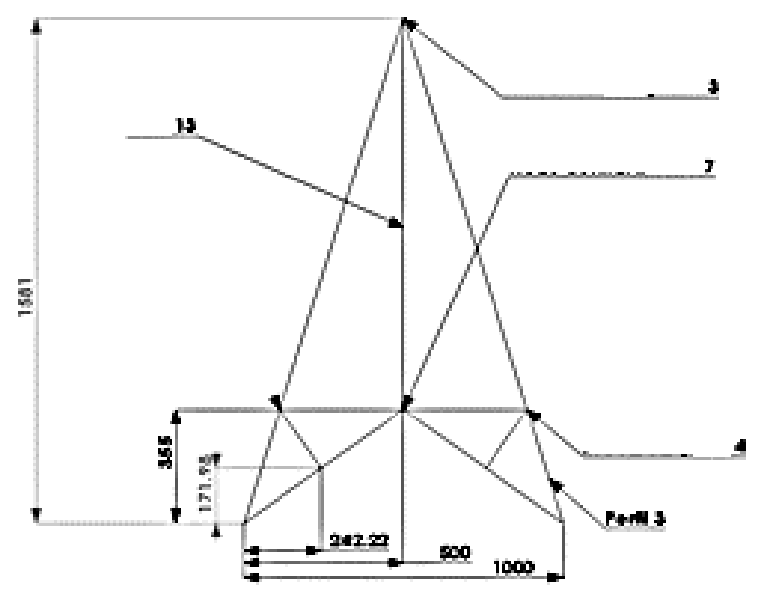

Fig 9. Profile of the truss with nodes named according to the given nomenclature in Autodesk Simulation Mechanical (measurements in $\mathrm{mm}$ ).

A free-body diagram of the structure is shown in Fig. 10.

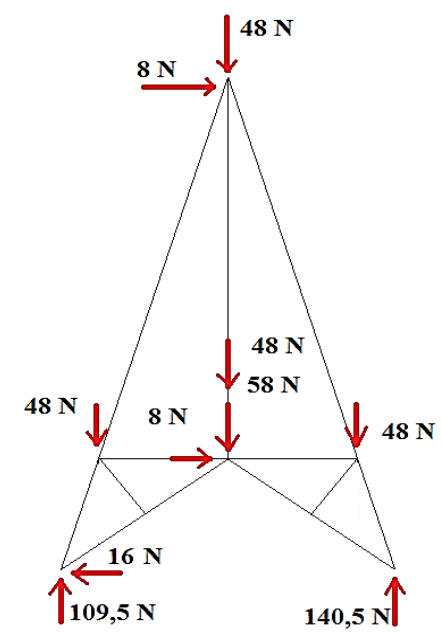

Fig 10. Free body diagram of the truss.

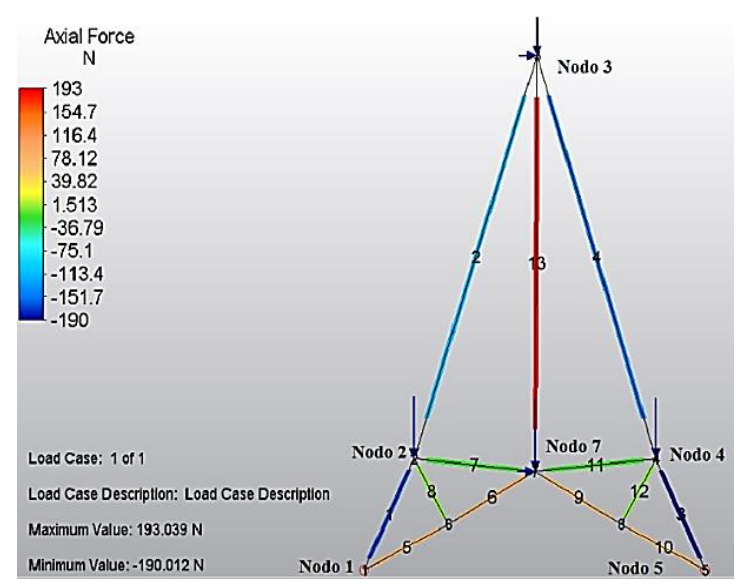

Fig 11. Structural analysis of the truss using the computer tool Autodesk Simulation Mechanical

The analysis of the truss is then carried out by means of the computer program Autodesk Simulation Mechanical, which provides the numerical values of the reactions in the supports, the internal loads to which each element is subjected (structural profile) and the way in which the truss may become deformed. Fig. 11 shows the analysis of the truss, which shows the axial internal loads of each element, likewise they are numbered and indicate the elements and nodes by means of numbers.

Design of the elements or structural profiles of the truss. Based on the tensile or compression forces that support the elements of the fence, we proceed to the determination of the stresses caused by internal loads in each element, considering that each element that forms the structure supports axial loads that generate traction and compression normal stresses [16]. Since the structure does not support live loads, its size is small compared to roof structures, and since most of the loads are dead, it is designed from the normal stress equation given by (13).

$$
S_{E}= \pm \frac{F_{A, I}}{A_{E}}
$$

$S_{E}$ : Normal stress that support the element $[\mathrm{Pa}], F_{A, I}$ : internal axial load in the element $[\mathrm{N}], A_{E}$ : minimum area of the transversal section of the element $\left[\mathrm{m}^{2}\right]$. 
The design equation of the elements subjected to simple static loads is given by the equation 14 :

$$
S \leq S_{d}=\frac{\text { material resistence } S_{u} \text { o } S_{y}}{N}
$$

Where $\mathrm{S}$ is the maximum stress to which the element is subjected. This equation can be used with the yield stress $S_{y}$ or with the ultimate stress $S_{u}$ of the material, in this case the creep resistance $S_{y}$ is considered in equation 14 in order to avoid failure due to plastic deformation.

Design of the loaded beam. The design of the loaded beam is made based on the design equation presented above, where the loads supported by the beam produce normal bending stresses. Observing the bending moment diagrams, the critical point is in the middle of the beam where the bearing is supported. Calculating the normal stress, it has:

$$
S=\frac{M_{F} * C}{I}
$$

The design of the connection elements of the structure is not presented, but all its dimensioning is also important for the construction part.

Modeling the wind turbine by using the solidworks computational tool: the entire design process of the physical components of the wind turbine was presented based on the application of the different design theories for the different load conditions of the component elements. Thanks to the design process, the necessary dimensions of the component elements were determined to allow an adequate mechanical resistance to the loads, minimum deformations and stability in the support structure, as well as the selection of the relevant materials of each element, connection forms or union, functionality, aesthetics and manufacturing costs. The dimensions thus determined, and the shape of the elements were modeled by using the Solidworks computational tool. The modeling process consists of obtaining 3D of each component element giving it its corresponding shape and the required dimensions. Subsequently, the assembly process is passed through the tools provided by the program, such as positional relationships. The general assembly of the wind turbine is presented in Fig. 12.

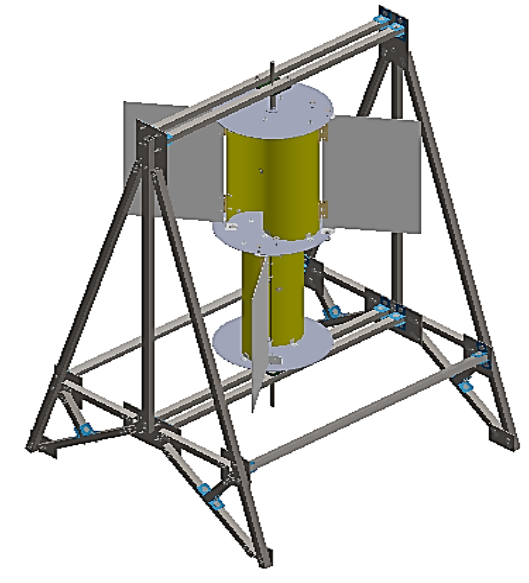

Fig. 12. Three-dimensional view of the general assembly of the wind turbine.

Simulation of air flow through the rotor of the Savonius wind turbine: Initially a dynamic simulation of the wind turbine rotor is executed, for this it is required to have the solid modeling of the rotor and once this is obtained, a volume must be defined of control which encloses the rotor, and it is there where certain border conditions are established as the different thermodynamic properties (Pressure, Temperature, Enthalpy, etc.). Another region of analysis is the rotating region in which the surface objectives are defined, understood as thermodynamic properties or dynamic variables that are desired to be ascertained during the development of the analysis. The ambient pressure and the average temperature of the place were respectively defined as $86 \mathrm{kPa}$ and $21^{\circ} \mathrm{C}$, in addition the wind speed for the analysis is handled with $8 \mathrm{~m} / \mathrm{s}$, the same with which the design process was carried out.

The pressure gradients as shown in Fig. 13 in the different concave and convex parts of the rotor generate resultant drag forces in each portion of the rotor which acting on a distance produce a net torque that in turn allows the rotation of the rotor. To obtain a better appreciation of the pressure distribution in the rotor and a closer approximation, an external flow analysis with the static rotor is performed.

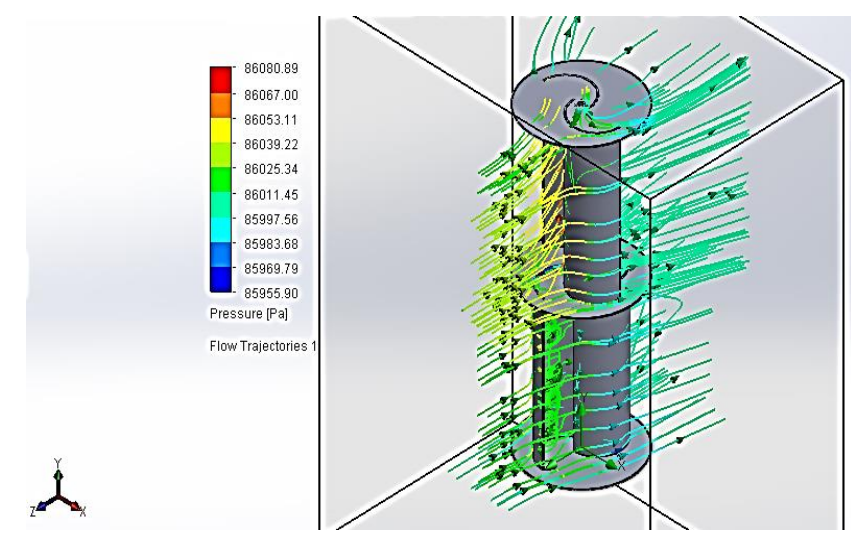

Fig 13. Pressure distribution in the rotor in external flow.

In the previous figure it can be seen that the highest pressure (yellow lines) is given on the concave part of the rotor blade. The distribution of pressures can also be seen in the floor plan shown in Fig. 14. 


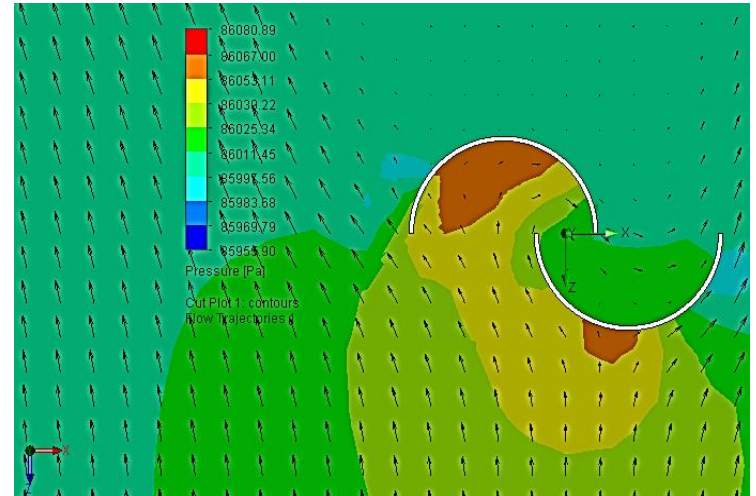

Fig 14. Pressure distribution in the rotor plane.

Analyzing the distribution of pressures, it is observed that the highest pressure is produced on the concave side of the blade and in the convex part a lower pressure is distributed. This differential of pressure and consequently a difference in the drag forces on the blades causes the torque generated by the drag force on the concave side to be greater compared to the torque generated by the drag force on the convex side, allowing that the rotation of the rotor is given. Also, for this case, the distribution of speeds in the floor plan for the static case of the rotor is presented in the following figures.

In the Fig. 15 and 16, it is observed that the geometric configuration of the Savonius rotor (overlap) contributes to the air circulation from one blade to the other one, thus increasing its induced torque, since part of the circulating air increases the drag force in each concave part. Through the analysis, other dynamic variables and thermodynamic properties were determined, such as the forces on the blades, the torque, and the density of the air. The following table provides the value of the dynamic variables and thermodynamic properties.

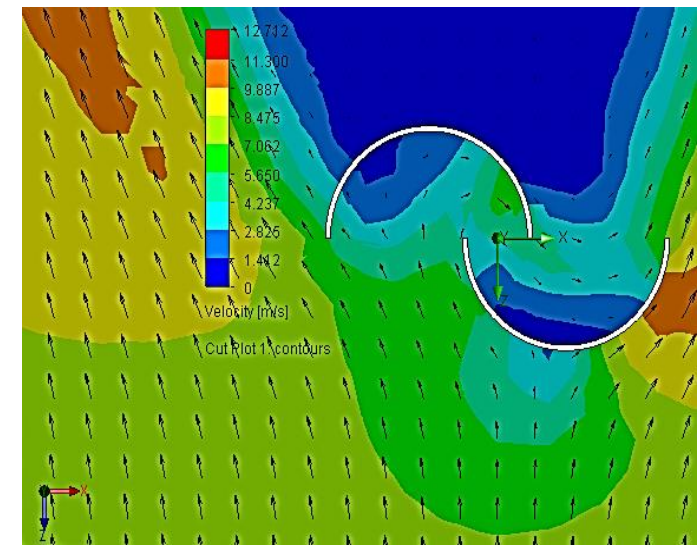

Fig 15. Speed distribution in the rotor plane for $\varphi=0^{\circ}$ upper stage.

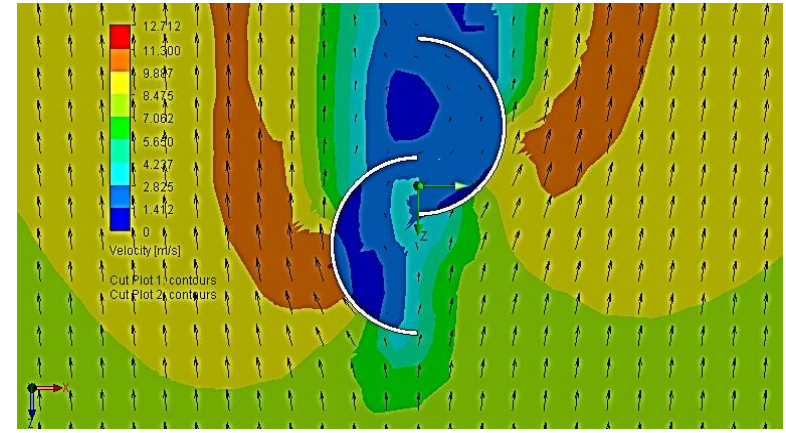

Fig 16. Distribution of speeds in the rotor plane for the position $\varphi=90^{\circ}$ lower stage.

TABLE I

DYNAMIC VARIABLES AND THERMODYNAMIC PROPERTIES DETERMINED BY DYNAMIC FLUID ANALYSIS FOR THE ROTOR WITHOUT PANELS.

\begin{tabular}{ccccc}
\hline \hline $\begin{array}{c}\text { Dynamic variable } \\
\text { and } \\
\text { thermodynamic } \\
\text { property }\end{array}$ & $\begin{array}{c}\text { Minimum } \\
\text { value }\end{array}$ & $\begin{array}{c}\text { Maximum } \\
\text { value }\end{array}$ & $\begin{array}{c}\text { Mean } \\
\text { value }\end{array}$ & $\begin{array}{c}\text { S.I } \\
\text { Unity }\end{array}$ \\
\hline $\begin{array}{c}\text { Total pressure } \\
\text { X- velocity }\end{array}$ & 86036.76 & 86036.77 & 86036.77 & $\mathrm{~Pa}$ \\
y- velocity & 0.004 & 0.005 & 0.004 & $\mathrm{~m} / \mathrm{s}$ \\
$\quad \begin{array}{c}\text { Z- velocity } \\
\text { Normal force in Z }\end{array}$ & 7.018 & 0.019 & 0.018 & $\mathrm{~m} / \mathrm{s}$ \\
$\begin{array}{c}\text { Density } \\
\text { Static torque (axis } \\
\text { y) }\end{array}$ & 1.02 & 7.484 & 7.483 & $\mathrm{~m} / \mathrm{s}$ \\
$\begin{array}{c}\text { Dynamic torque } \\
\text { (axis y) }\end{array}$ & 0.395 & 0.396 & 0.396 & $\mathrm{Nm}$ \\
\hline \hline
\end{tabular}

According to the results obtained presented in the table I, it can be expressed that the air velocity in the rotor presents only one predominant component along the coordinate axis $\mathrm{z}$ (wind incidence) and in the rest the values are null, meaning this there is a one-dimensional flow. Due to this, the force exerted by the air flow on the rotor has a component along the coordinate axis $\mathrm{z}$, in the direction of air flow, the other force components are zero. As for the torque, it presents a value of $M_{Y}=0,396 \mathrm{Nm}$ in the negative direction of the coordinate axis.

\section{PHYSICAL ASSEMBLY OF THE SAVONIUS WIND TURBINE}

The process of cutting with frame-saw was used to give the required dimensions to the different structural profiles. These dimensions were obtained from the design process, and were reflected in the plan of the structure, where said measures were guaranteed with the use of the meter and squares. In the same way, this tool was used to cut the angles of the structure, the rotor and the PVC tube to obtain the blades. The mechanical shear was used throughout the process of cutting the gills to give the required dimensions. On the other hand, the circular shape of the final plates was obtained thanks to the oxyfuel process. Table II presents the process of cutting metals by oxyfuel. 
TABLA II

MATERIALS AND MECHANICAL ELEMENTS USED IN THE ASSEMBLY OF THE WIND TURBINE.

\begin{tabular}{|c|c|c|c|}
\hline $\begin{array}{l}\text { Type of } \\
\text { element }\end{array}$ & $\begin{array}{l}\text { Dimensions and } \\
\text { specifications }\end{array}$ & Material & $\begin{array}{c}\text { Obtention } \\
\text { process }\end{array}$ \\
\hline $\begin{array}{l}\text { Tubular } \\
\text { structural } \\
\text { profile of } \\
\text { square } \\
\text { section }\end{array}$ & $\begin{array}{l}26 \mathrm{~mm} \times 26 \mathrm{~mm} \times \\
6 \mathrm{~m} \text { length }\end{array}$ & $\begin{array}{l}\text { Steel AISI } \\
\text { SAE } 1020\end{array}$ & $\begin{array}{l}\text { Cold rolled } \\
\text { (cold } \\
\text { lamination) }\end{array}$ \\
\hline Steel plate & $3 \mathrm{~mm}$ thick & $\begin{array}{l}\text { Steel AISI } \\
\text { SAE } 1020\end{array}$ & $\begin{array}{l}\text { Cold rolled } \\
\quad \text { (cold } \\
\text { lamination) }\end{array}$ \\
\hline $\begin{array}{l}\text { Angle } \\
\text { connector } \\
\text { structure }\end{array}$ & $\begin{array}{c}38 \mathrm{~mm} \text { (equal } \\
\text { wings) x } 1 \mathrm{~m} \\
\text { length, thickness } 2 \\
\mathrm{~mm}\end{array}$ & ASTM A36 & lamination \\
\hline $\begin{array}{l}\text { Angle } \\
\text { connector } \\
\text { blade end } \\
\text { plate }\end{array}$ & $\begin{array}{c}20 \mathrm{~mm} \text { (equal } \\
\text { wings) x } 1.5 \mathrm{~mm} \\
\text { thick }\end{array}$ & ASTM A36 & lamination \\
\hline $\begin{array}{l}\text { Union bolts } \\
\text { of the } \\
\text { structure }\end{array}$ & $\begin{array}{l}\text { Nominal Diameter } \\
1 / 4 ", \text { number of } \\
\text { threads per inch } 20\end{array}$ & $\begin{array}{l}\text { Steel AISI } \\
\text { SAE } 1020\end{array}$ & $\begin{array}{l}\text { Industrial } \\
\text { process }\end{array}$ \\
\hline Rotor shaft & Diameter 5/8 " & $\begin{array}{l}\text { Steel AISI } \\
\text { SAE } 1020\end{array}$ & $\begin{array}{c}\text { Cold } \\
\text { lamination }\end{array}$ \\
\hline Final dishes & 14 gauge & $\begin{array}{l}\text { Steel AISI } \\
\text { SAE } 1020\end{array}$ & $\begin{array}{c}\text { Cold } \\
\text { lamination }\end{array}$ \\
\hline blades & $\begin{array}{l}6 \text { "in diameter x } 1 \\
\mathrm{~m} \text { in length. }\end{array}$ & PVC & $\begin{array}{l}\text { Industrial } \\
\text { process }\end{array}$ \\
\hline Panel & $\begin{array}{l}\text { Panels of } 490 \mathrm{~mm} \times \\
300 \mathrm{~mm} \times 2.5 \mathrm{~mm} \\
\text { thickness }\end{array}$ & Acrylic & $\begin{array}{l}\text { Industrial } \\
\text { process }\end{array}$ \\
\hline bearing & UCF 201-8 & steel & $\begin{array}{l}\text { Industrial } \\
\text { process }\end{array}$ \\
\hline hinge & Ref. 3 IMDUMA & steel & $\begin{array}{l}\text { Industrial } \\
\text { process }\end{array}$ \\
\hline
\end{tabular}

The main shaft of the rotor required certain dimensions according to its design process. The tree was then submitted to the turning process with its initial dimensions to bring it to said dimensions. During the mechanization of the tree, it became necessary to use a bezel to support the tree due to its length of $1.5 \mathrm{~m}$. The use of the calibrator and micrometer as measuring elements was essential to guarantee the required dimensions of said mechanical element.

The drilling operations enabled the drilling of the holes in structural elements, brackets, angles, blades, tree and end plates. These holes will allow through them pass the union bolts of the structure and the rotor, where the adjustment between bolt and hole is a fit with clearance. It became necessary to make different assemblies to carry out all the various drilling operations required. The assembly that was carried out for the drilling process in the laboratory of Machines

After carrying out all the manufacturing operations required, the final assembly is carried out, which can be seen in Fig. 17.

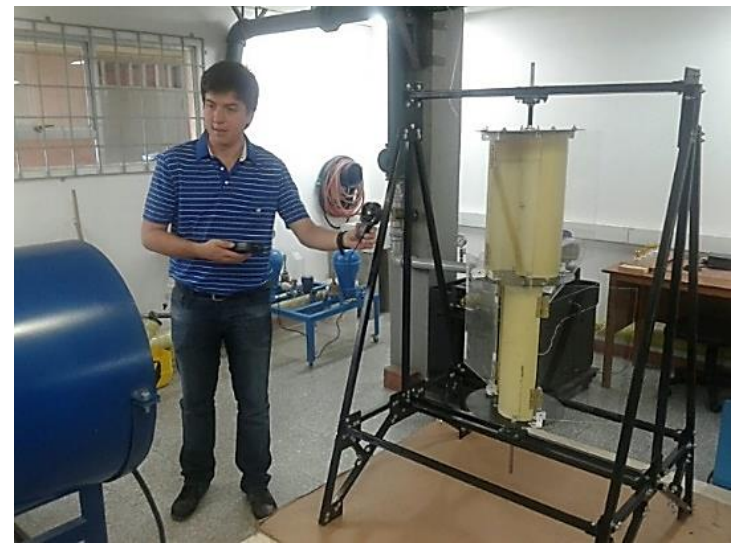

Fig 17. Assembly of the wind turbine.

\section{EXPERIMENTAL TESTS OF THE SAVONIUS WIND TURBINE}

Experimental tests were performed on the wind turbine without panels for which measurements were made of wind speed, angular speed of the rotor, and static torque corresponding to different wind speeds. The tests were carried out in the wind tunnel of the Laboratory of Fluids and Hydraulic Machines of the Technological University of Pereira with the collaboration of Eng. Yamal Mustafá Iza M.Sc., which through the use of a frequency inverter can be varied its angular velocity, which means having a variable wind speed. To carry out the measurement of the experimental data during the tests, the following measurement devices were used:

Anemometer model AM-4206, resolution for wind speed measurement of $0.01 \mathrm{~m} / \mathrm{s}$ and resolution for temperature measurement of $0.1{ }^{\circ} \mathrm{C}$. The wind speed data is measured at $70 \mathrm{~cm}$ from the rotor.

$\checkmark \quad$ LT Lutron DT 2236 tachometer, resolution $0.1 \mathrm{rev} /$ min.

The obtained angular velocity curve is shown as a function of the wind speed in Fig. 18.

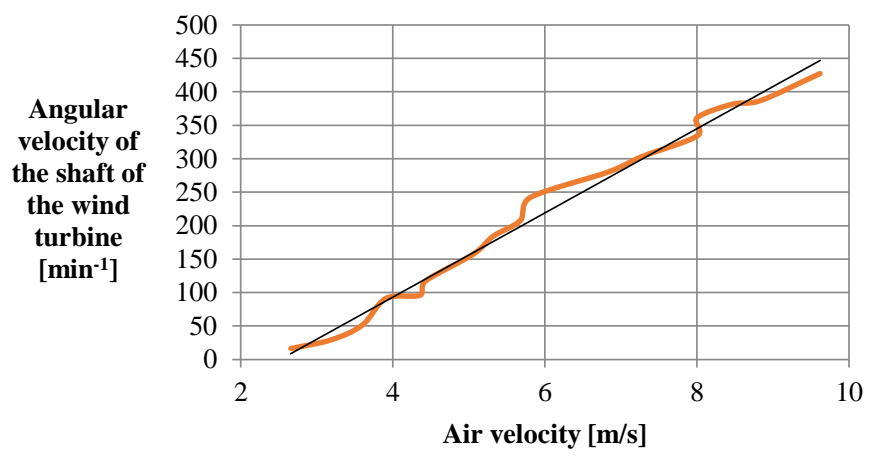

Fig 18. Angular velocity as a function of wind speed.

The curve obtained from torque as a function of the wind speed is shown in Figure 19. For this case the torque is measured statically, with the difference that in this case the wind affects the rotor to different speeds, achieving balance of the rotor with the addition of different counterweights. 


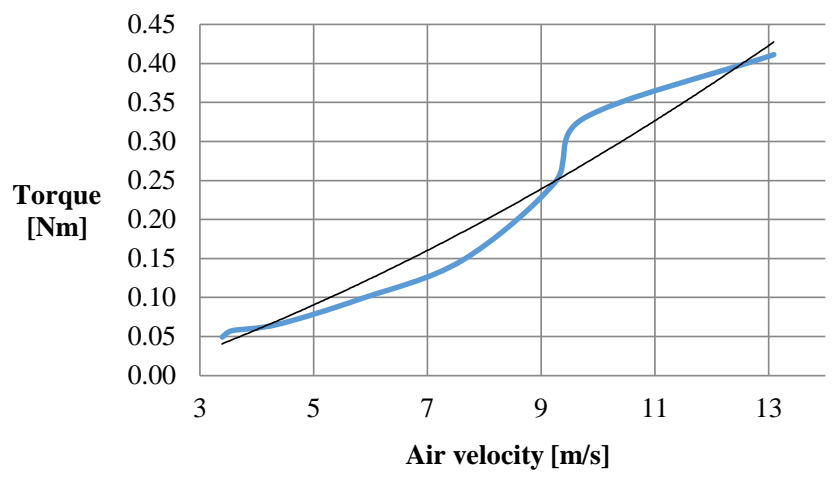

Fig 19. Torque as a function of the wind speed for the rotor.

Fig. 20 shows the mechanical power as a function of the wind speed, for this case the mechanical power was determined theoretically from the experimental data of static torque and angular speed of the rotor corresponding to table 8.3. The determination of the mechanical power is determined by (16)

$$
P_{r}=M_{T} \cdot \omega
$$

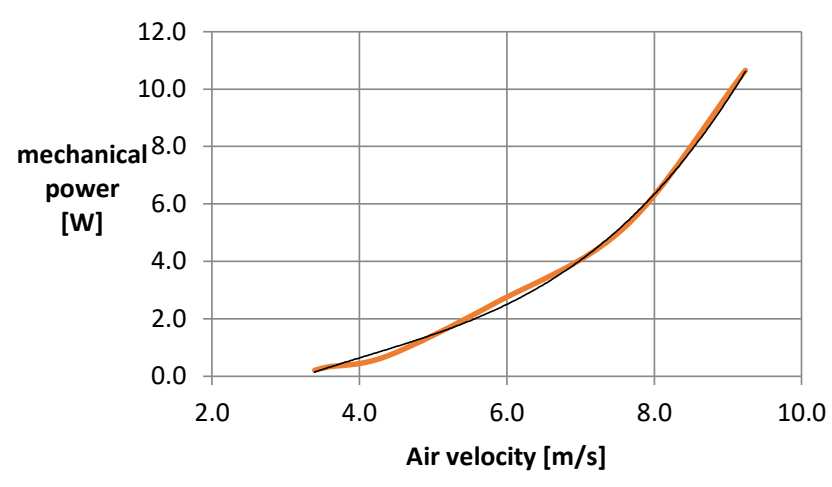

Fig 20. Mechanical power as a function of wind speed.

\section{ANALYSIS OF EXPERIMENTAL RESULTS}

According to the tabulated experimental data, the following can be expressed:

- It can be observed in the curve of figure 22 that there is a linear relationship between the wind speed and the angular speed of the rotor, thus confirming the TSR (Tip Speed Ratio). On the other hand, the angular velocity of the rotor without panels is much higher compared to that obtained from the rotor with panels, because the panels increase the inertia of the system and also restrict movement.

- The behavior of the data of the curve of figure 23 of torque as a function of the wind speed have a functional relationship of order 2 .

- The graph in figure 24 shows the behavior of the mechanical power data as a function of the wind speed, in which a cubic tendency is observed. This is what is expected since theoretically the mechanical power of a wind turbine varies with the cube of the wind speed.

\section{CONCLUSIONS}

- The parameters of the wind energy were characterized, especially the variability of the wind speed in the whole Colombian national territory.

- The data taken from the meteorological unit of the ceiling of the Faculty of Mechanical Engineering showed that the average wind speed is $1 \mathrm{~m} / \mathrm{s}$ for this reason this site is not suitable for this type of wind turbine. Places in the coastal areas of Colombia represent a good wind potential for the use of this type of energy.

- The design of the wind turbine was based on the scientific articles investigated, theories studied and the experiences of other authors.

- Applied design theories allowed to select the appropriate materials and the required dimensions, to obtain a physical model that guarantees the operating conditions based on which it was designed.

- The modeling of the wind turbine was developed using the Solidworks computer tool, based on the sizing obtained through the design process.

- The analysis of the behavior of the flow allowed to know the distribution of pressures in the blades, the effect of overlap, the velocity field on the rotor and the torque generated by the drag forces.

- The different manufacturing processes required were carried out in order to carry out the physical assembly of the Savonius wind turbine.

- Experimental tests of the turbine with the axial fan of the wind tunnel were developed in the laboratory of Fluids and Hydraulic Machines of the Faculty of Mechanical Engineering of the Technological University of Pereira.

\section{ACKNOWLEDGMENT}

We thank and acknowledge the great work that each of the teachers, administrators, workers and students of the Technological University of Pereira have done for providing us with their knowledge, teaching, time, service, collaboration and friendship during the stage of academic formation and Professional as Mechanical Engineer. 


\section{REFERENCES}

[1] N. Vaughn. "Introduction to renewable energy" United States: Boca Raton CRC: Press Taylor \& Francis group, 2011, 350p. ISBN 13: 978-1-4398-9120-9. [Online]. Available:

https://www.loot.co.za/product/vaughn-c-nelson-introduction-torenewable-energy/pvnj-2740-ga50.

[2] R. Hugh. "Wind power, The wind generation," [Online]. Available: http://web.ing.puc.cl/ power/paperspdf/CapituloEolico.pdf.

[3] E. H Lysen, "Introduction to wind energy," Wind energy. Consultancy services wind energy developing countries. 2nd ed. Netherlands: 1983, 311p.

[4] D. B. Sanz, I. Cruz. "Guide on small wind technology," Arias Montano Graphics. Madrid: 2012. 118p. [Online]. Available: https://www.fenercom.com/publicacion/guia-sobre-tecnologiaminieolica-2012/

[5] Aracuan. Region of turbulence around a building [online]. Available: http://www.aracuan.com.ar/turbulencia.htlm.

[6] J. V. Akwa, H. A. Vielmo, and A. P. Petry. "Review on the performance of Savonius wind turbines," ScienceDirect, Renewable and sustainable energy reviews. Pp. 3054-3064, June 2012, 16 (2012) 3054-3064, [Online]. DOI: 10.1016/j.rser.2012.02.056

[7] J. L. Menet, N. Bourabaa. "Increase in the Savonius rotors efficiency via parametric investigation," Ecole Nationale Superieure d'ingenieurs en Informatique Automatique Mecanique Énergetique Électronique de Valenciennes ENSIAME, [online].Available: http://educypedia.karadimov.info/library/23_1400_jeanlucmenet_0 1.pdf.

[8] F. Wenehenubun, A. Saputra, and H. Sutanto. "An experimental study on the performance of Savonius wind turbines related with the number of blades," ScienceDirect, 2nd International Conference on Sustainable Energy Engineering and Application, ICSEEA 2014, 68 (2015) 297 - 304, [online]. DOI: 10.1016/j.egypro.2015.03.259.

[9] A. A. Kadam, S. S. Patil. "A review study on Savonius wind rotors for accessing the power performance," IOSR Journal of Mechanical and Civil Engineering, pp. 18-24, Second National Conference on Recent Developments in Mechanical Engineering 18 | Page M.E.Society's College of Engineering, Pun [Online]. Available: https://www.researchgate.net/publication/281899860_A_Review_ Study_on_Savonius_Wind_Rotors_for_Accessing_the_Power_Per formance.

[10] M. H. Ali. "Experimental comparison study for Savonius wind turbine of two and three blades at low wind speed," International Journal of Modern Engineering Research IJMER, Vol. 3, Issue. 5, pp. 2978-2986, Oct. 2013, [Online]. Available: http://www.ijmer.com/papers/Vol3_Issue5/CJ3529782986.pdf

[11] D. Torres. "Design of a low power vertical shaft wind generator. Degree work, Faculty of Mechanical Engineering, Technological University of Pereira, Pereira, Risaralda, 2015 [online]. Available: repositorio.utp.edu.co/dspace/handle/11059/5145.

[12] J. A. Menet. "Double step Savonius rotor for local production of electricity: a design study," ScienceDirect, Feb. 2004, [online]. DOI: $10.1016 /$ j.renene.2004.02.011

[13] Colombia. energy mining planning unit EMPU. Institute of hydrology, meteorology and environmental studies IDEAM. Atlas of Wind and Wind Energy of Colombia, 2006 [online]. Available: http://www.upme.gov.co/Atlas_Viento.htm.

[14] J. F. Manwell, J. G. McGowan. "Wind energy explained. Theory, design and application," Global energy concepts. 2nd Ed. USA: Wiley, 2010, pp. 1-100. [online]. Available: http://ee.tlu.edu.vn/Portals/0/2018/NLG/Sach_Tieng_Anh.pdf.

[15] K. N. Morshed, M. Rahman and G. Molina. "Wind tunnel testing and numerical simulation on aerodynamic performance of a threebladed Savonius wind turbine," International Journal of Energy and Environmental Engineering, 2013 [online]. Available: https://link.springer.com/article/10.1186/2251-6832-4-18.

[16] L. V. Vanegas. "Design of machine elements," Mechanical Design, vol. 1, 1ra Ed, Pereira, Risaralda, Colombia. UTP, 2016. [online]. Available: http://blog.utp.edu.co/lvanegas/dis1/.

[17] NTN. Bearings catalog [online]. Available: http://www.ntnamericas.com/es/website/documents/brochures-andliterature/catalogs/bearing-units\%202400-IX.pdf.

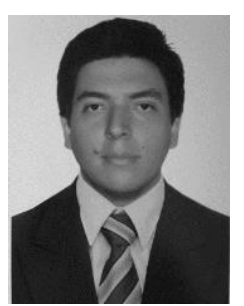

Andrés Felipe Rodriguez Valencia was born on September 14, 1992 in La Victoria Valle (Colombia). He completed his undergraduate studies in Mechanical Engineering (2010-2016) at the Technological University of Pereira (UTP). During the realization of the career, he was academic monitor of the department of mathematics and monitor of the laboratory of fluids and hydraulic machines. At a professional level, he worked in the maintenance area at the company Trapiche Biobando S.A.S, where the company's assembly activities were supported, in the area of extraction and processing. He worked at Accedo Colombia S.A.S in the commercial sales part of the company. In 2017, he started as Professor of the Faculty of Mechanical Engineering, has directed the courses of Static and Hydraulic Machines and Fluids Laboratory. With the Department of Mathematics, he has guided the Linear Algebra courses. He is candidate for the master's degree in Mechanical Engineering in the line of manufacturing and design processes of the same university, where he graduated from, since 2017.

ORCID: https://orcid.org/0000-0002-0540-8019

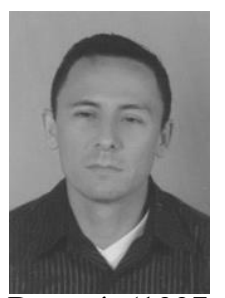

Edgar Alonso Salazar Marín was born on June 6, 1973 in Santa Rosa de Cabal. (Risaralda / Colombia). He's Mechanical Engineer and did doctored studies in Polytechnical University of Catalonia- Spain (2003-2007), He has master's studies in mechanical engineering of Andes UniversityBogotá (1997-1998) and Master in Automatic Systems of Production - UTP (2002-2004). He worked as researcher in Coffee Research National Center (Cenicafé) from 1999 to 2000. $\mathrm{He}$ has worked as professor in Technology Faculty on Technological University of Pereira since 2000 and he's developed different projects about renewable energies, like Solar systems (thermal and photovoltaic), solar vehicles and conversion from combustion vehicles to electric vehicles. ORCID: https://orcid.org/0000-0003-2873-245X 